
\section{sustainable consumption}

Citizens' views on

\section{In brief}

- More than 1000 citizens in eleven European countries discussed consumption policy within a standardised setting.

- Citizens demand environmentally friendly, socially responsible and economically affordable products and services.

- Their main opinion: policy-makers should take ambitious steps to foster sustainable and environmentally friendly consumption in Europe.

\section{What is it about?}

Our current consumption patterns are increasingly putting pressure on the environment and society: scarcity of resources and energy, global warming and exploitative labour conditions are only a few examples. The resulting environmental and societal challenges threaten humankind's prosperity. For instance, household consumption has consistently risen over the last 25 years: per capita, Austrians use approx. 30 per cent more energy and they own more cars. Food consumption, too, has increased over the past decade. At the same time, citizens have increasingly developed an awareness regarding sustainability. For example, sales figures for organic products have been rising steadily for some time.

But what does sustainable, i.e. environmentally friendly and socially responsible, consumption mean and how can we achieve it? One main step is to minimise the use of natural resources and toxic materials as well as emissions, waste and pollutants over a product's life cycle so as not to jeopardise the needs of future generations. Another important step is to provide socially responsible conditions along the life cycle and secure affordability for consumers.
In order to make consumption more sustainable, citizens ask for comprehensive changes. On the one hand, changes are needed within manufacturing and supply, i.e. from the producers, but on the other hand, consumers themselves have a responsibility for their shopping behaviour as their consumption patterns carry great potential for provoking change from the demand side.

Consequently, citizens are essential agents for sustainable consumption. Their knowledge, shaped by their daily experiences, is a valuable source when it comes to identifying opportunities for policies promoting sustainable consumption. To elicit this knowledge, a large-scale citizen consultation was held with more than 1000 citizens in eleven EU countries on 25 October 2014. During the consultation, citizens had the opportunity to clarify what should be done from their point of view and which measures would be feasible in their eyes.

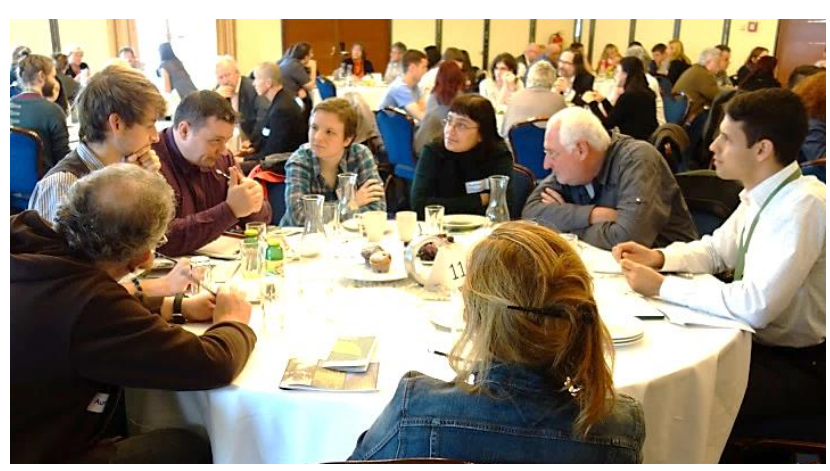

Citizens across Europe discuss sustainable consumption

Prior to the consultation, participants had received an information booklet which included an overview of the effects of consumption and options of how to steer consumption with different political instruments. The information material was provided in order to help citizens broaden their knowledge thus making their personal decisions and arguments on the discussed topic more robust. It also provided citizens with the necessary knowledge to discuss complex environmental policy issues.

In Austria, 104 people attended the consultation and discussed the topic throughout the day. Participants were selected according to demographic criteria to guarantee diversity with regard to sex, age, education, occupation, living environment (urban/rural) and the level of societal engagement.

\section{Basic data}

Project title: Europe Wide Views on Sustainable

Project team:

Duration:

Funded by: Consumption - WP7/ PACITA

Website:
Sotoudeh, M., Capari, L. 04/2011 - 03/2015 EU/FP7 citizenconsultation. pacitaproject.eu 


\section{Key results}

One highlight from the eleven consultations is the citizens' great willingness to voluntarily reduce private consumption, a point of view articulated by citizens across all participating countries. Nevertheless, barriers seem to exist, which compromise the articulated willingness to reduction. The gap between personal attitude and actual behaviour can, however, be bridged by certain measures.

More than half of the citizens demand more investment into public mobility to allow for a reduction in the use of private means of transport. In addition, citizens very clearly favoured tax incentives for alternatives to individual car transport.

Product quality was also identified as an important field of action as citizens called for greater product longevity and an extension to mandatory warranties, especially for electronic devices such as mobile phones or TV sets. These arguments strongly favour the idea of transforming the European economy into a so-called circular or closed-loop economy where (almost) no waste occurs as it is either reused or recycled in various processes.

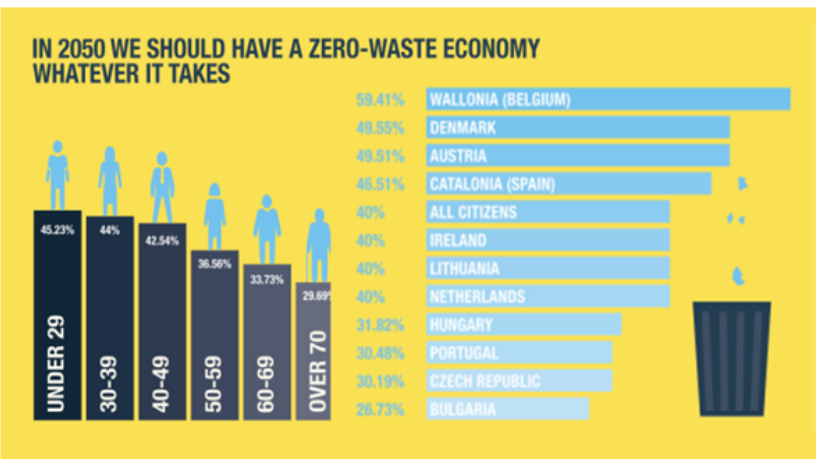

Citizens strongly advise to take measures towards a circular economy with no waste

Younger citizens in particular see a need for future waste reduction, especially in view of Europe increasingly producing more and more waste, of which most is exported to nonOECD countries. This is a clear indicator for a growing sensibility for and awareness of increasing amounts of waste in today's society.

During a conference in Brussels, representatives of the European Parliament, the European Commission and stakeholders from industry, retail and environmental organisations were presented with the results from the consultations. The representatives unanimously agreed that the consultations' results represent a valuable contribution to the ongoing debate on transforming Europe's economy into a circular economy.

\section{What to do?}

Informed citizens have specific demands and recommendations for policies on sustainable consumption:

- Make sustainable consumption affordable. Environmentally friendly and socially responsible products must be affordable. This includes not only sustainable products at lower prices, but also higher taxes on products with a negative impact on the environment and society.

- Ensure greater product life. Almost three quarters of the citizens were of the opinion that the EU should extend mandatory warranties and enforce higher manufacturing standards thereby allowing for longer product life. They also are in strong favour of making it easier and cheaper to repair broken products.

- Provide better eco-efficient alternatives to conventional car transport. In order to minimise individual car transport, alternatives are needed. Moreover, public transport systems must be improved. Citizens also advocate for higher taxes on vehicles polluting the environment to a greater degree than environmentally friendly ones.

These results aim at supporting the development and implementation of social acceptable policies. Herein, citizens see shared responsibilities: including citizens themselves in their role as consumers but also public authorities - EU and member states - as well as businesses and the industry. Simply leaving this to market mechanisms will not be enough to reach the ambitious goals of sustainable consumption.

\section{Further reading}

Jørgensen, M.-L., Lindegaard Juul, K. (2015) Europe Wide Views on Sustainable Consumption: From European Citizens to Policy Makers, Policy Report epub.oeaw.ac.at/ita/PACITA/pacita-citizenconsultation-policy-report.pdf

\section{Contact}

Leo Capari

Email: tamail@oeaw.ac.at

Phone: $+43(1) 51581-6582$

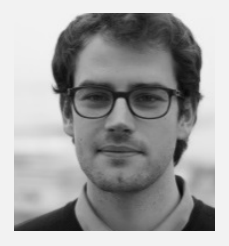

